\title{
Experimental Verification of the Performance of the Floor Cooling System in Comparison with the Ceiling Cooling System While Maintaining Thermal Comfort in the Environment
}

\author{
Pavol Mičko ${ }^{1, *}$, Andrej Kapjor ${ }^{1}$, Šimon Kubas ${ }^{1}$, and Martin Vantúch ${ }^{1}$ \\ ${ }^{1}$ Department of Power Engineering, Faculty of Mechanical Engineering, University of Zilina, \\ Univerzitna 1, 01026 Zilina, Slovak Republic
}

\begin{abstract}
The trend of constantly increasing energy prices can be observed especially in the increased demands on the thermal insulation properties of building structures. The possibilities of reducing the energy intensity of residential buildings also include the right choice of technology for heating, cooling and hot water preparation. Different cooling systems have different proportions of convection and radiant components. This results in a variety of temperature profiles, and thus also directly affect the quality of the environment in terms of thermal comfort. For efficient heating, it is therefore best to choose a cooling system with a minimum temperature gradient in both the horizontal and vertical directions. At the same time, however, the investment costs for the cooling system must be considered. From this point of view, it seems to be most advantageous to use one system for both heating and cooling. From the point of view of comfort, the most suitable choice of cooling system is ceiling cooling. On the contrary, this system is less suitable for heating compared to the floor system. Therefore, if you are considering the design of a system that will be the greater part of the operation for heating the building and during the summer months will be used to increase thermal comfort by cooling in buildings with lower heat loads [1].
\end{abstract}

\section{Introduction}

The acquisition costs of a heat pump are significantly higher compared to a gas condensing boiler [2]. However, if we use one source for both heat production and cold production, the total purchase price is consequently lower than for one separate heat source and a separate cold source. Such use is then even more advantageous than using biomass fuel, the energy value of which is increased by waste heat [3]. Most heat pumps can also operate in reversible mode and can produce cold. The system designed in this way can replace cooling systems in the summer months with minimal investment costs. However, the performance of a refrigeration device is limited by several factors that limit its use. When used in combination with a floor radiant system, it is necessary to consider a suitable

*Corresponding author: pavol.micko@,fstroj.uniza.sk 
temperature gradient due to the risk of condensation of water vapor on the cooled surface of the structure. An unfavourable factor is also the exclusion of the influence of natural convection and the accumulation of cold air above the floor. These facts can have a major impact on thermal comfort and comfort in a refrigerated room. Thermal comfort is a function of several variables, including: indoor air temperature, indoor air velocity, humidity, effective temperature, thermal resistance of clothing and metabolism of the human body. The distribution of air temperatures has the major influence on achieving thermal comfort. A heating system that can create a uniform and even temperature distribution is the most advantageous in terms of comfort. The value of the horizontal and vertical temperature gradient also belongs to the factors of local thermal comfort. Its value is therefore monitored when assessing the quality and comfort of the environment [4].

\section{Measurement of thermal comfort}

The most important component of the environment, the thermal-humidity microclimate, serves to assess the suitable thermal condition of interiors - thermal comfort. Its disruption affects homoiothermia. A person with his mental and physical condition can adapt to a certain microclimate. There is a range (neutral zone) in which the requirements for adaptation are minimal and one feels best in it. Part of this zone is also thermal comfort. It is conditioned by subjectively pleasant feelings, which do not burden the human thermoregulatory system, with an objectively balanced heat balance. In this state, one does not feel cold or. excessive heat [6].

It is clear from the above definition of thermal comfort that a necessary condition for the balance between the interior and the subject (human being) is the transfer of the produced human heat to the interior without significant loading of the thermoregulatory element. The thermal equilibrium is mathematically expressed by equation (1) [5].

$$
q_{m} \pm q_{w}-q_{e}-q_{d}= \pm q_{s} \pm q_{k}
$$

Where: $q_{m}$ - heat flux density from metabolism $\left[\mathrm{W} / \mathrm{m}^{2}\right], q_{w}$ - heat flux density from human work $\left[\mathrm{W} / \mathrm{m}^{2}\right], q_{e}$ - heat flux density (loss) by evaporation $\left[\mathrm{W} / \mathrm{m}^{2}\right], q_{d}$ - heat flux density (loss) by respiration $\left[\mathrm{W} / \mathrm{m}^{2}\right], q_{c l}$ - heat flux density through clothing $\left[\mathrm{W} / \mathrm{m}^{2}\right], q_{s}$ - radiant heat flux density $\left[\mathrm{W} / \mathrm{m}^{2}\right], q_{k}$ - heat flux density by convection $\left[\mathrm{W} / \mathrm{m}^{2}\right]$.

Equation (1) must apply to create an optimal thermal condition in the interior for people who are in it for a long time. The average surface temperature of the skin and the amount of sweat excreted are the only physiological variables that express the state of thermal comfort. Using these two quantities, the degree of loading of the thermoregulatory system in conditions of thermal comfort is expressed. In the state of thermal comfort, the average skin surface temperature $\theta_{k}\left[{ }^{\circ} \mathrm{C}\right]$ and the heat flux density (loss) by evaporation of $q_{e}$ are expressed by the mathematical relations (2) and (3):

$$
\begin{gathered}
\theta_{k}=5.7-0.0275 \cdot\left(q_{m}-q_{w}\right) \\
q_{e}=3.05 .10^{-3} \cdot\left(256 . \theta_{k}-3373-p_{i}\right)+0.42 \cdot\left(q_{m}-q_{w}-58.15\right)
\end{gathered}
$$

After substituting equations (2) and (3) into equation (1), we can express the state of thermal comfort as a function of six independent quantities (thermal comfort factors).

$$
f\left(q_{q}, R_{c l}, \theta_{i}, p_{i}, v_{i}, \theta_{u}\right)=0
$$


Where: $q_{q}$ - total heat flux density from the human body $(q q=q m \pm q w)\left[\mathrm{W} / \mathrm{m}^{2}\right], R_{c l}$ thermal resistance of clothing $\left[\mathrm{m}^{2} \mathrm{~K} / \mathrm{W}\right]([\mathrm{CLO}]), \theta_{i}$ - indoor air temperature $\left[{ }^{\circ} \mathrm{C}\right], p_{i}$ partial pressure of indoor air water vapor $[\mathrm{Pa}], v_{i}$ - indoor air flow rate $[\mathrm{m} / \mathrm{s}], \theta_{u}$ - effective temperature of surrounding surfaces $\left[{ }^{\circ} \mathrm{C}\right]$.

The first two parameters characterizing the state of thermal comfort, and thus $q_{q}$ and $R_{c l}$ are subjective. These parameters vary individually from user to user. The remaining four parameters are objective and physically-measurable quantities determining the state of the environment.

\subsection{Measurement in a thermostatic chamber}

To accurately determine the boundary conditions for measuring the thermal comfort of floor cooling, we performed the measurement in a thermostatic chamber for testing and evaluating the performance of radiators and convectors according to EN 442 part 2. Chamber length is $4 \pm 0.02 \mathrm{~m}$, width $4 \pm 0.02 \mathrm{~m}$ height $3 \pm 0.02 \mathrm{~m}$. During cooling, cooling water with a supply temperature of $17{ }^{\circ} \mathrm{C}$ flows through the floor system distribution. This temperature is limited due to local thermal discomfort in the foot area but also due to the risk of condensation of water vapor on the floor. Fluorescent lamps are used as the thermal load of the building, which convert $99 \%$ of the electrical energy into heat. The fluorescent lamps are evenly distributed in the corners of the room in a total of 12 pieces. The indoor air temperature shall be controlled by the master system to maintain equilibrium conditions and the reference room temperature shall be in the range of $26 \pm$ $0.5^{\circ} \mathrm{C}$. The measurement of the parameters of the thermal-humidity microclimate of the indoor air took place at five stations according to the following Figure 1.

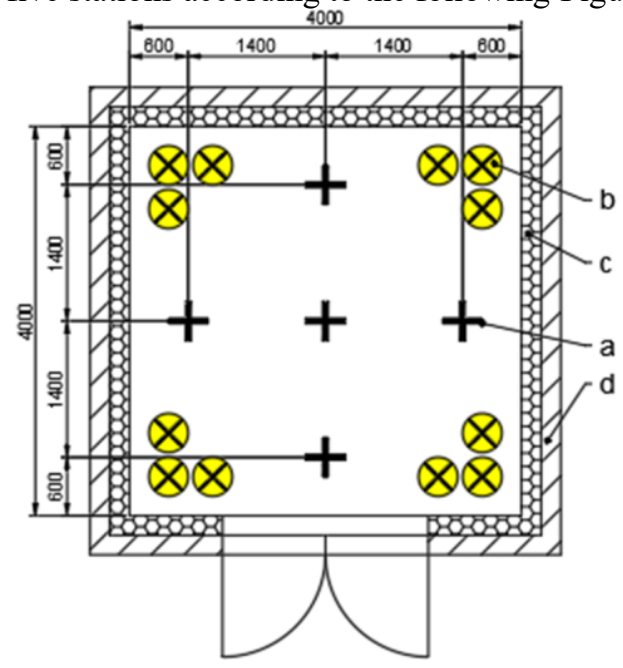

Fig. 1. Floor plan of the thermostatic chamber: a) opinion measuring the heat-humidity microclimate, b) fluorescent lamp - thermal load, c) thermal insulation, d) construction of the thermostatic chamber.

\subsection{Measuring device}

We used a ComfortSense device from Dantec Dynamics to measure the thermal comfort in the thermostatic chamber. The measuring elements of the device meet the standards EN 13 182, ISO 7726 and ISO 7730. The device is designed for the development and research of heating cooling and ventilation systems, using multipoint measurement of 
temperature and air speed. To measure temperature profiles and indoor air velocity, three measuring elements were used: $T 1$ (at the height of the ankles, $0.1 \mathrm{~m}$ from the ground), $T 2$ (at the height of the center of gravity, $1.1 \mathrm{~m}$ from the ground) and $T 3$ (at the height of the head, $1.7 \mathrm{~m}$ from the ground). For the range of measured temperatures, the inaccuracy of the measuring elements is guaranteed to be $\pm 0.2{ }^{\circ} \mathrm{C}$. The measurement of the mean radiant temperature, from which we can derive the operating temperature, was provided by an OT member located at a height of $1.1 \mathrm{~m}$ from the ground, which is measured with an accuracy of $\pm 0.2{ }^{\circ} \mathrm{C}$. The last objective parameter, the partial pressure of water vapor in the air, was recorded by the RH member, which expressed this pressure in the form of relative humidity in the interior with an accuracy of $\pm 1.5 \%$. All objective parameters of the heathumidity microclimate were measured during the equilibrium state in a thermostatic chamber where the average temperature of all sensors was $26 \pm 0.5{ }^{\circ} \mathrm{C}$. The remaining objective parameters were chosen according to the estimate of the expected activity or the value according to the standard was chosen. The selected total heat flux density from the human body represented a standing slightly active user, where the production is expected to be 90 to $100 \mathrm{~W} \cdot \mathrm{m}^{-2}$. The thermal resistance of clothing for measuring the thermal comfort of cooling systems is set at $0.5 \mathrm{CLO}$, ie $0.078 \mathrm{~m}^{2} . \mathrm{K}^{-\mathrm{W}^{-1}}$. The measuring device with individual measuring members can be seen in Figure 2.

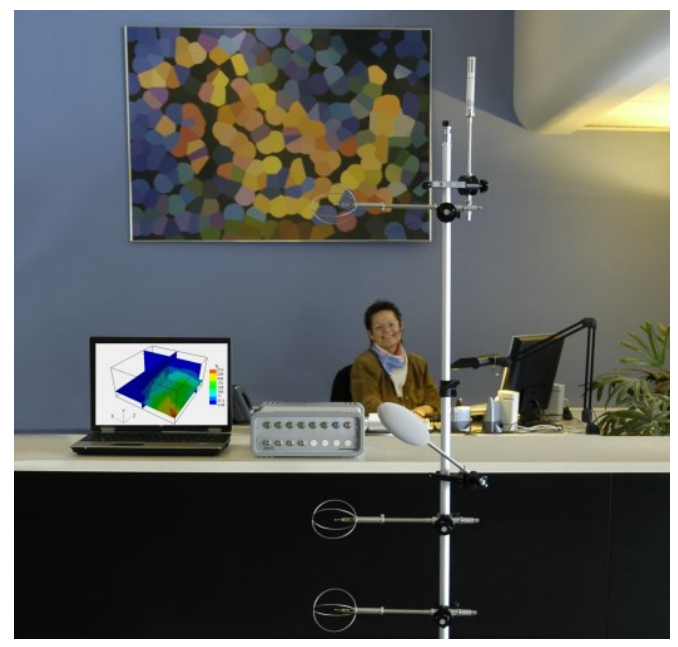

Fig. 2. Measuring device ComfortSense - Dantec [7].

\section{Variants of measuring thermal comfort}

To objectively evaluate the thermal comfort of underfloor radiant cooling, a measurement of thermal comfort for the ceiling radiant cooling system was first performed, which will serve as a standard for the evaluation of the floor system. The second in order will be the measurement of the floor cooling system, which will cover the same heat load. The variant with a reduced temperature drop to cover the heat load will follow. The last measurement will record the quality of the indoor environment with reduced thermal load, so as to achieve thermal comfort in the room. 


\subsection{Measurement of environmental parameters for ceiling radiant cooling}

The temperature of the cooling water supply to the ceiling panels was set to $17^{\circ} \mathrm{C}$, and the indoor air temperature was set to $26^{\circ} \mathrm{C}$. The control system of the thermostatic chamber itself determined the flow of cooling water and the resulting cooling capacity was $950 \mathrm{~W}$. The values of the measured environmental parameters for ceiling cooling are given in Table 1. In Figure 3 shows the room temperature $\theta_{i}$. In Figure 4 shows the air flow rate $v_{i}$.

Table 1. Ceiling cooling environment parameters.

\begin{tabular}{|c|c|c|c|c|}
\hline $\begin{array}{c}\text { Measuring } \\
\text { element }\end{array}$ & $\begin{array}{c}\text { Air flow } \\
\text { velocity } \boldsymbol{v}_{\boldsymbol{i}}[\mathbf{m} / \mathbf{s}]\end{array}$ & $\begin{array}{c}\text { Temperature } \\
\boldsymbol{\theta}_{\boldsymbol{i}}\left[{ }^{\circ} \mathbf{C}\right]\end{array}$ & $\begin{array}{c}\text { Operative } \\
\text { temperature }\left[{ }^{\circ} \mathbf{C}\right]\end{array}$ & $\begin{array}{c}\text { Relative } \\
\text { humidity [\%] }\end{array}$ \\
\hline$T 1$ & 0.04 & 26.4 & & \\
\hline$T 2$ & 0.09 & 26.4 & & \\
\hline$T 3$ & 0.11 & 26.4 & & \\
\hline$O T$ & & & 25.6 & \\
\hline$R V$ & & & & 35.2 \\
\hline
\end{tabular}
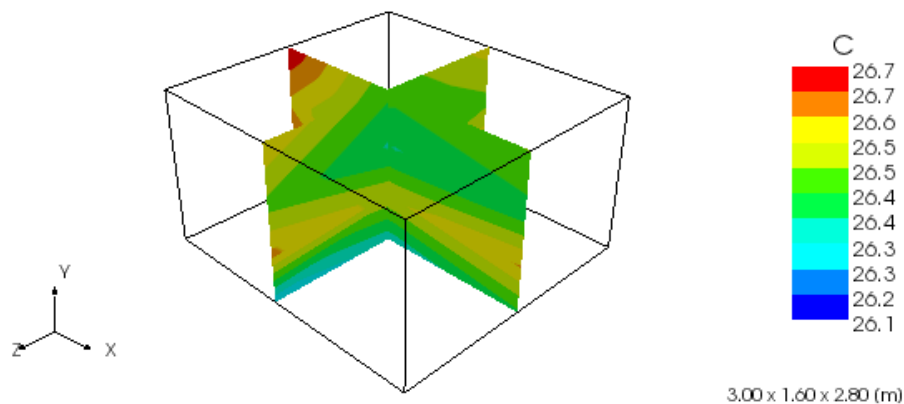

Fig. 3. Air temperature distribution $\theta_{i}$ for ceiling cooling.
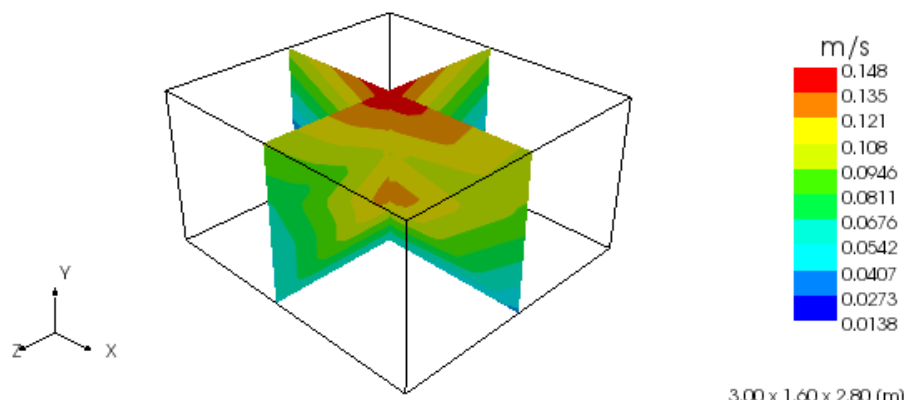

$3.00 \times 1.60 \times 2.80(\mathrm{~m})$

Fig. 4. Distribution of air flow velocity $v_{i}$ during ceiling cooling.

\subsection{Measurement of environmental parameters for floor radiant cooling with the same heat load as ceiling cooling}

The temperature of the cooling water supply was kept at $17{ }^{\circ} \mathrm{C}$ to prevent condensation of water vapor on the floor panels. The heat load was retained from the previous ceiling 
measurement. The values of the measured environmental parameters for floor cooling are given in Table 2. In Figure 6 shows the air flow rate $v_{i}$ in the room, and Figure 5 shows the room temperature $\theta_{i}$.

Table 2. Floor cooling the same heat load environment parameters.

\begin{tabular}{|c|c|c|c|c|}
\hline $\begin{array}{c}\text { Measuring } \\
\text { element }\end{array}$ & $\begin{array}{c}\text { Air flow } \\
\text { velocity } \boldsymbol{v}_{\boldsymbol{i}}[\mathbf{m} / \mathbf{s}]\end{array}$ & $\begin{array}{c}\text { Temperature } \\
\boldsymbol{\theta}_{\boldsymbol{i}}\left[{ }^{\circ} \mathbf{C}\right]\end{array}$ & $\begin{array}{c}\text { Operative } \\
\text { temperature }\left[{ }^{\circ} \mathbf{C}\right]\end{array}$ & $\begin{array}{c}\text { Relative } \\
\text { humidity [\%] }\end{array}$ \\
\hline$T 1$ & 0.03 & 28.7 & & \\
\hline$T 2$ & 0.03 & 31.5 & & \\
\hline$T 3$ & 0.06 & 31.9 & & \\
\hline$O T$ & & & 29.3 & \\
\hline$R V$ & & & & 27.9 \\
\hline
\end{tabular}
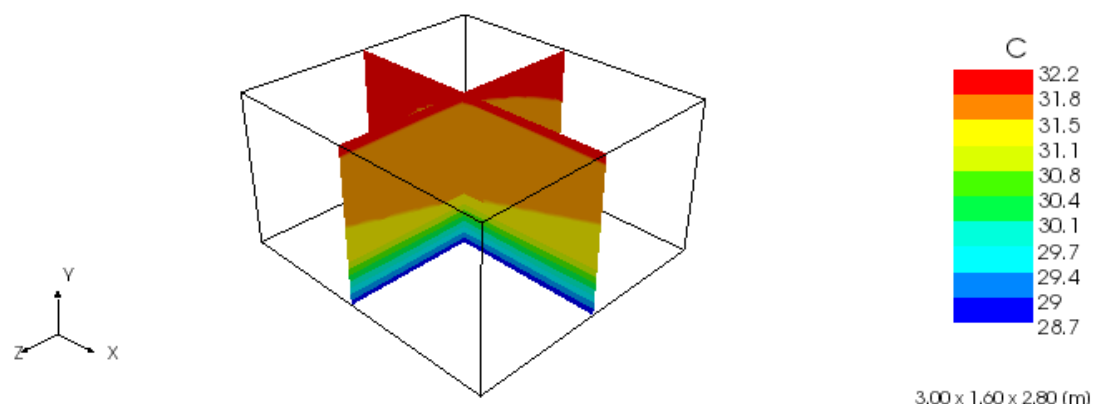

Fig. 5. Air temperature distribution $\theta_{i}$ for floor cooling with the same heat load.
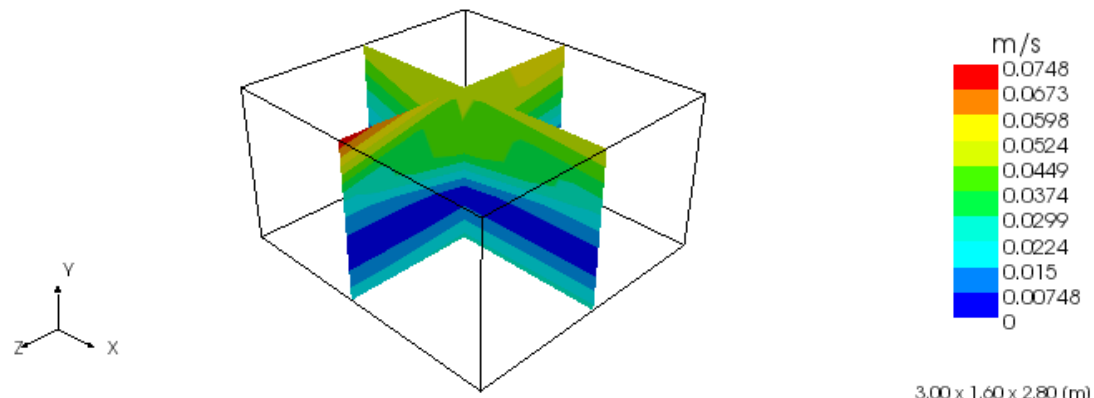

$3.00 \times 1.60 \times 2.80(\mathrm{~m})$

Fig. 6. Distribution of air flow velocity $v_{i}$ during floor cooling with the same heat load.

\subsection{Measurement of environmental parameters for underfloor radiant cooling with reduced cooling water supply temperature}

With underfloor cooling with a reduced flow temperature, the heat load and the internal temperature requirement remained the same. The supply temperature to the floor panels was adjusted, which increased the thermal gradient and thus the performance of the cooling system. The flow temperature was set at $10.5^{\circ} \mathrm{C}$. The values of the measured 
environmental parameters for floor cooling with a reduced flow temperature are given in Table 3. In Figure 8 shows the air flow rate $v_{i}$ in the room, and Figure 7 shows the room temperature $\theta_{\mathrm{i}}$.

Table 3. Floor cooling environment parameters with reduced cooling water supply temperature.

\begin{tabular}{|c|c|c|c|c|}
\hline $\begin{array}{c}\text { Measuring } \\
\text { element }\end{array}$ & $\begin{array}{c}\text { Air flow } \\
\text { velocity } \boldsymbol{v}_{\boldsymbol{i}}[\mathbf{m} / \mathbf{s}]\end{array}$ & $\begin{array}{c}\text { Temperature } \\
\boldsymbol{\theta}_{\boldsymbol{i}}\left[{ }^{\circ} \mathbf{C}\right]\end{array}$ & $\begin{array}{c}\text { Operative } \\
\text { temperature }\left[{ }^{\circ} \mathbf{C}\right]\end{array}$ & $\begin{array}{c}\text { Relative } \\
\text { humidity [\%] }\end{array}$ \\
\hline$T 1$ & 0.01 & 24.9 & & \\
\hline$T 2$ & 0.02 & 28.0 & & \\
\hline$T 3$ & 0.06 & 28.5 & & \\
\hline$O T$ & & & 25.9 & \\
\hline$R V$ & & & & 35.6 \\
\hline
\end{tabular}
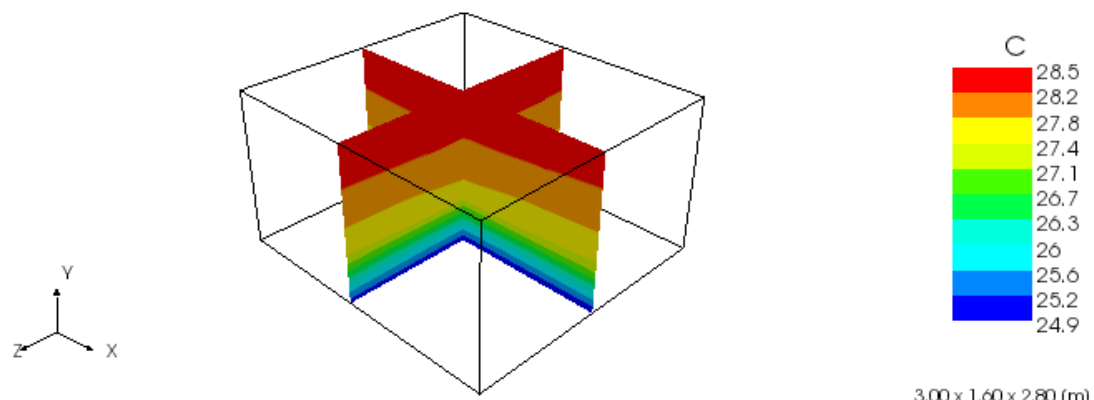

$3.00 \times 1.60 \times 2.80(\mathrm{~m})$

Fig. 7. Air temperature distribution $\theta_{i}$ for floor cooling with reduced cooling water supply temperature.
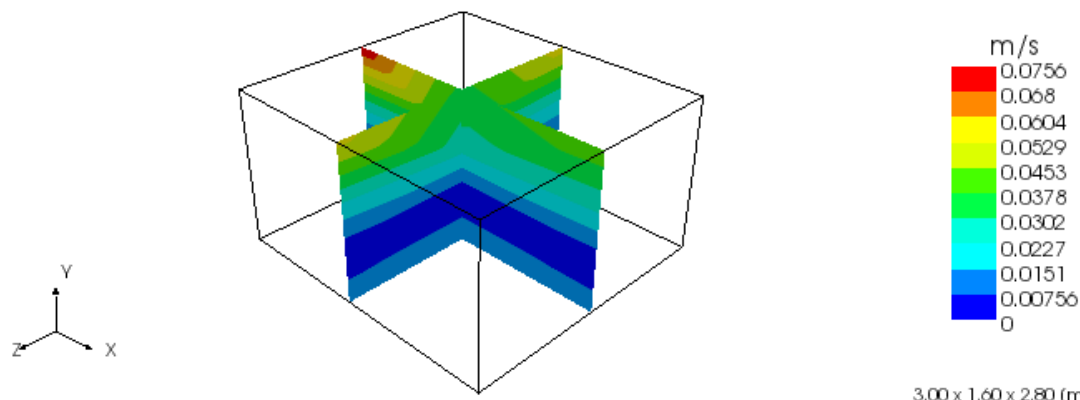

$3.00 \times 1.60 \times 2.80(\mathrm{~m})$

Fig. 8. Distribution of air flow velocity $v_{i}$ for underfloor cooling with reduced cooling water supply temperature.

\subsection{Measurement of environmental parameters for floor radiant cooling with reduced heat load}

For floor cooling with reduced heat load, we proceeded in the same way as for ceiling cooling. The cooling water supply temperature is set again to $17^{\circ} \mathrm{C}$ and the temperature demand in the thermostatic chamber remains at $26^{\circ} \mathrm{C}$. When setting the required 
temperature in the interiors, the magnitude of the heat load stabilized at $520 \mathrm{~W}$. The values of the measured environmental parameters for floor cooling with reduced heat load are given in Table 4. In Figure 10 shows the air flow rate vi in the room, and Figure 9 shows the room temperature $\theta_{i}$.

Table 4. Parameters of the floor cooling environment with reduced heat load.

\begin{tabular}{|c|c|c|c|c|}
\hline $\begin{array}{c}\text { Measuring } \\
\text { element }\end{array}$ & $\begin{array}{c}\text { Air flow velocity } \\
\boldsymbol{v}_{\boldsymbol{i}}[\mathbf{m} / \mathbf{s}]\end{array}$ & $\begin{array}{c}\text { Temperature } \\
\boldsymbol{\theta}_{\boldsymbol{i}}\left[{ }^{\mathbf{C}} \mathbf{C}\right]\end{array}$ & $\begin{array}{c}\text { Operative } \\
\text { temperature }\left[{ }^{\circ} \mathbf{C}\right]\end{array}$ & $\begin{array}{c}\text { Relative } \\
\text { humidity }[\%]\end{array}$ \\
\hline$T 1$ & 0.02 & 25.1 & & \\
\hline$T 2$ & 0.03 & 27.0 & & \\
\hline$T 3$ & 0.03 & 27.2 & & \\
\hline$O T$ & & & 25.7 & \\
\hline$R V$ & & & & 39.5 \\
\hline
\end{tabular}
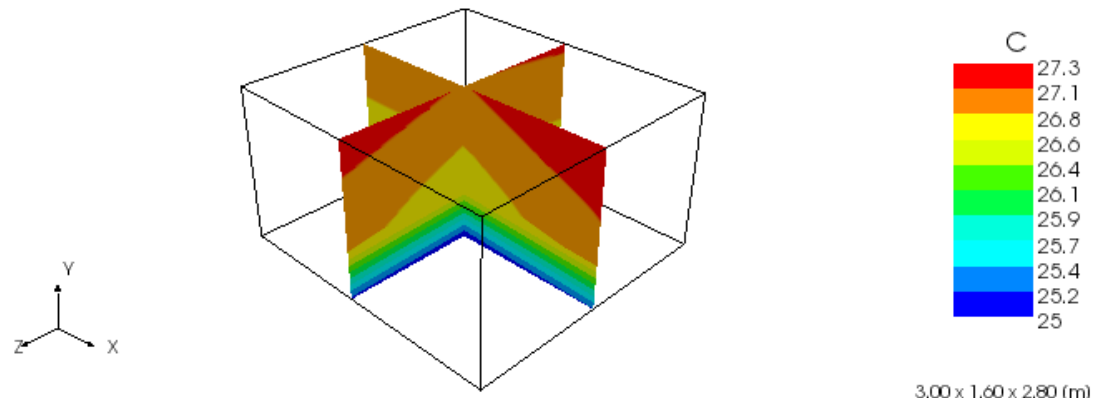

Fig. 9. Air temperature distribution $\theta_{i}$ for floor cooling with reduced heat load.
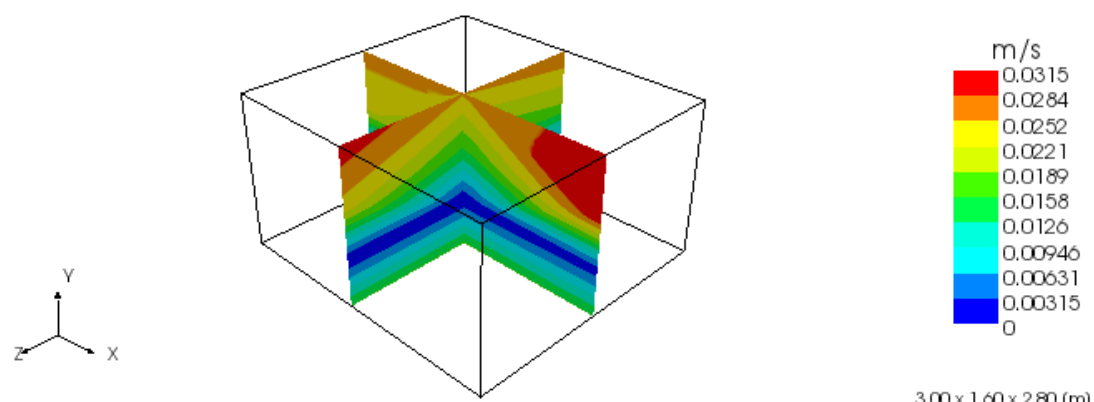

$3.00 \times 1.60 \times 2.80(\mathrm{~m})$

Fig. 10. Distribution of air flow velocity $v_{i}$ in underfloor cooling with reduced heat load.

\section{Evaluation of thermal comfort}

From the measured objective parameters of the thermal-humidity microclimate, we can use the previous equations to express the PMV and PPD indices for individual cooling systems. The values are given in Table 5. 
The floor temperature is the most important parameter for underfloor cooling and heating. If the temperature gradient is set incorrectly, the comfort system could otherwise be uncomfortable. With floor cooling, the temperature gradient is approximately $2{ }^{\circ} \mathrm{C}$ higher than ceiling radiant cooling. The advantage of this system is especially in the very low air flow rate. It is important to control the local thermal discomfort, as the calculation of the PPD index does not include all parameters affecting the thermal comfort in the environment. From floor cooling measurements, we found that it has only half the capacity of ceiling cooling. When measuring floor cooling with a heat load of $950 \mathrm{~W}$, (heat load covered by ceiling cooling), this system was unsatisfactory. The room temperature was too high and the PPD index reached up to $40 \%$. To cover this loss, it was necessary to lower the temperature of the cooling water supply, which had a negative effect on local thermal comfort. At the same time, in real conditions, water vapor would condense on the floor. In these two measurements, floor cooling can be described as unsatisfactory. In the last measurement of floor cooling, we reduced the heat load to $520 \mathrm{~W}$. The floor temperature stabilized at $19.6^{\circ} \mathrm{C}$. The minimum recommended floor temperature for contact with bare feet is $22.5^{\circ} \mathrm{C}$. This temperature can be uncomfortable for the human body. Although not within the recommended temperature range, it is still within the recommended PPD index range. This negative impact can be eliminated by appropriately selected system operation. For example, the use of cooling at a time when no one is in the building

Table 5. PMV and PPD index values for cooling systems.

\begin{tabular}{|c|c|c|c|c|c|}
\hline Cooling system & $\begin{array}{c}\text { Measuring } \\
\text { element }\end{array}$ & $\begin{array}{c}\text { Operative } \\
\text { temperature } \\
{\left[{ }^{\circ} \mathrm{C}\right]} \\
\end{array}$ & $\begin{array}{c}\text { Mean radiation } \\
\text { temperature } \\
{\left[{ }^{\circ} \mathrm{C}\right]} \\
\end{array}$ & PMV [-] & PPD [\%] \\
\hline \multirow{3}{*}{ 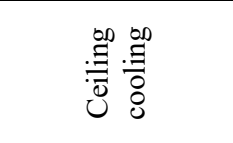 } & $\mathrm{T} 1$ & 25.5 & 25.1 & -0.15 & 5.47 \\
\hline & $\mathrm{T} 2$ & 25.5 & 25.0 & -0.14 & 5.42 \\
\hline & $\mathrm{T} 3$ & 25.5 & 24.7 & -0.25 & 6.34 \\
\hline \multirow{3}{*}{ 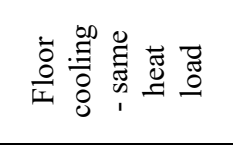 } & $\mathrm{T} 1$ & 29.4 & 29.7 & 1.10 & 30.46 \\
\hline & $\mathrm{T} 2$ & 29.4 & 28.1 & 1.28 & 39.41 \\
\hline & $\mathrm{T} 3$ & 29.4 & 27.5 & 1.21 & 35.94 \\
\hline \multirow{3}{*}{ 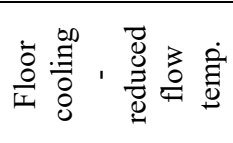 } & $\mathrm{T} 1$ & 25.7 & 26.1 & -0.23 & 6.12 \\
\hline & $\mathrm{T} 2$ & 25.7 & 24.2 & 0.06 & 5.07 \\
\hline & $\mathrm{T} 3$ & 25.7 & 23.9 & 0.07 & 5.11 \\
\hline \multirow{3}{*}{ 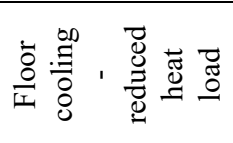 } & $\mathrm{T} 1$ & 25.3 & 25.4 & -0.33 & 7.21 \\
\hline & $\mathrm{T} 2$ & 25.3 & 24.4 & -0.12 & 5.32 \\
\hline & $\mathrm{T} 3$ & 25.3 & 24.2 & -0.11 & 5.24 \\
\hline
\end{tabular}

\section{Conclusion}

We evaluated the floor radiant cooling as less pleasant than the ceiling radiant cooling. The disadvantage of floor cooling is the absence of natural convection due to the lower density of warm air. This causes a stepwise temperature distribution. The advantage is the minimum air speed in the interior. Compared to ceiling radiant cooling, the cooling capacity is only half, approximately $30 \mathrm{~W} / \mathrm{m}^{2}$. Under heat load, where the ceiling radiant system can create an optimal environment, floor cooling is insufficient [8-10]. The performance of the floor system can be increased by lower cooling water temperature. 
However, this variant is unsuitable due to the low floor temperature and the risk of condensation on the floor. However, it can be used in areas where the humidity of the air and the device for its treatment are monitored. Increased performance could completely cover the heat load when there are no people in the room. Before users enter the room, the cold water supply temperature would be raised so that the floor temperature stabilizes at an acceptable value. According to the measurement results, underfloor cooling is not suitable for areas with a higher heat load, such as offices and rooms with a high proportion of glass walls. High potential for use is possible in areas with lower heat load. This includes, for example, family houses, where materials with higher thermal resistance are used for the perimeter structures, and the share of glazed areas is smaller. In such spaces, floor cooling can create a comfortable environment. The disadvantage of this system is the less comfortable floor temperature, but this can be eliminated by changing the performance of the system during the day depending on the presence of users. Thus, this system can be characterized as a low-cost system that is suitable for cooling family houses while its users are, if there are no users in it. After the arrival of users, the accumulated energy will be used for cooling in the ceiling and perimeter structures.

This article was supported by project KEGA - 048ŽU-4/2019 "Flow visualization in environmental engineering".

\section{References}

1. D. Petras, a kol., Nizkoteplotné vykurovanie a obnovitel'né zdroje energie, 54-57 (2001)

2. J. Jandacka, M. Holubcik, S. Papucik, R. Nosek, Acta Montanistica Slovaca, Combustion of pellets from wheat straw, 17, 283-289 (2012)

3. R. Nosek, M. Holubcik, Acta Facultitas Xylologiae Zvolen, Energy properties of air dry firewood, 58, 105-112 (2016)

4. S. Papucik, R. Nosek, R. Lenhard, Vykurovanie. 112-129 (2012)

5. D. Petras, a kol., Vykurovanie rodinných a bytových domov, 54-57 (2005)

6. M. Szekyova, K. Ferstl, R. Novy, Vetranie a klimatizácia, 71-74 (2004)

7. DANTEC DYNAMICS.: ComfortSense, [Online], dostupné na: https://www.dantec dynamics.com/comfortsense [3 December 2019], 2019

8. R. Lenhard, T. Puchor, Mathematical modelling of non-isothermal flow in buildings, EPJ Web of Conferences 143, (2017)

9. R. Lenhard, K. Kaduchova, J. Jandacka, Numerical Simulation in Indirectly heated hot Water Heater, Adv. Material Research, 875-877, 1693-1697 (2014)

10. R. Lenhard, J. Jandacka, A. Kapjor, EXPERIMENTAL FLUID MECHANICS 2008, (2008) 